\title{
RESEARCH
}

Open Access

\section{Changes in self-rated health and quality of life among Syrian refugees migrating to Norway: a prospective longitudinal study}

Jasmin Haj-Younes $^{1 *}$ D, Elisabeth Marie Strømme ${ }^{1}$, Jannicke Igland ${ }^{1}$, Bernadette Kumar ${ }^{2}$, Eirik Abildsnes ${ }^{3}$, Wegdan Hasha ${ }^{1}$ and Esperanza Diaz ${ }^{1,2}$

\begin{abstract}
Background: Forced migrants can be exposed to various stressors that can impact their health and wellbeing. How the different stages in the migration process impacts health is however poorly explored. The aim of this study was to examine changes in self-rated health $(\mathrm{SRH})$ and quality of life (QoL) among a cohort of adult Syrian refugees before and after resettlement in Norway.

Method: We used a prospective longitudinal study design with two assessment points to examine changes in health among adult Syrian resettlement refugees in Lebanon accepted for resettlement in Norway. We gathered baseline data in 2017/2018 in Lebanon and subsequently at follow-up one year after arrival. The main outcomes were good SRH measured by a single validated item and QoL measured by WHOQOL-BREF. We used generalized estimating equations to investigate changes in outcomes over time and incorporated interaction terms in the models to evaluate effect modifications.
\end{abstract}

Results: In total, 353 subjects participated in the study. The percentage of participants reporting good SRH showed a non-significant increase from 58 to $63 \%$ RR, $95 \% \mathrm{Cl}$ : $1.1(1.0,1.2)$ from baseline to follow-up while mean values of all four QoL domains increased significantly from baseline to follow-up; the physical domain from 13.7 to $15.7 \mathrm{~B}$, 95\%Cl: $1.9(1.6,2.3)$, the psychological domain from 12.8 to $14.5 \mathrm{~B}, 95 \% \mathrm{Cl}$ : $1.7(1.3,2.0)$, social relationships from 13.7 to $15.3 \mathrm{~B}, 95 \% \mathrm{Cl}$ : $1.6(1.2,2.0)$ and the environmental domain from 9.0 to $14.05 .1 \mathrm{~B}, 95 \% \mathrm{Cl}$ : $(4.7,5.4)$. Positive effect modifiers for improvement in SRH and QoL over time include male gender, younger age, low level of social support and illegal status in transit country.

Conclusion: Our results show that good SRH remain stable while all four QoL domains improve, most pronounced in the environment domain. Understanding the dynamics of migration and health is a fundamental step in reaching health equity.

Keywords: Self-rated health, Quality of life, Refugees, Transients and migrants

\footnotetext{
*Correspondence: jasmin.haj-younes@uib.no

'Department of Global Public Health and Primary Care, University of Bergen, PO Box 7800, 5020 Bergen, Norway

Full list of author information is available at the end of the article
}

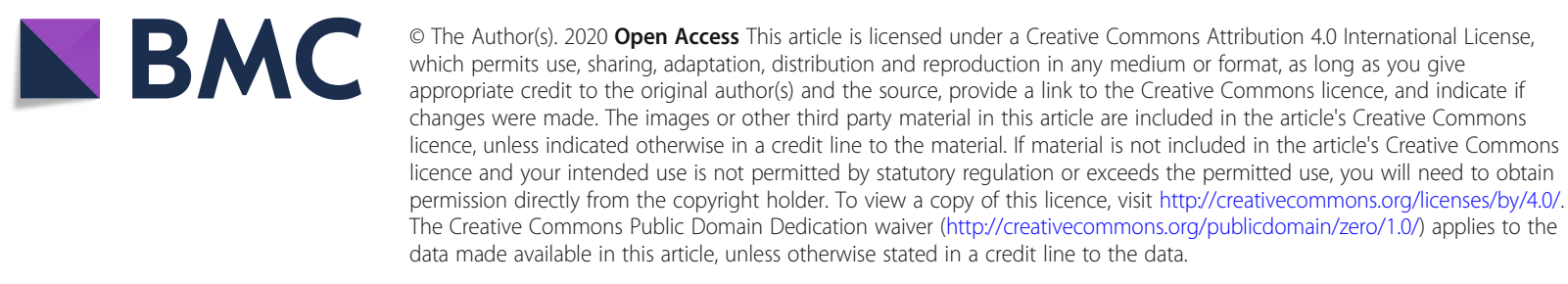




\section{Introduction}

We are witnessing a time in which forced migration is surging and the need to ensure protection, health, and wellbeing of people on the move is ever so vital. This sentiment is echoed in the Sustainable Development Goals of leaving no one behind [1]. In every stage of the migration process (pre-migration, during migration and after resettlement) impact on health and wellbeing is inevitable [2, 3]. Possible health risks and potential protective factors influence the health outcomes of the migrant, and there is an ongoing attempt to identify the relevance of each of these factors [4].

Populations at risk of poor health and health care disparities are generally considered as being vulnerable [5]. Migrants may encounter several barriers to health care because of their legal status and due to economic and social marginalization. Forced migrants differ from other types of migrants in that they are survivors of persecution, violence, and war - factors that might add to their health vulnerability. Hence, it remains unclear if the selection described in the 'healthy migrant effect' that postulates migrants' health advantage compared to both citizens in the home country and in the host country holds true for refugees and other forced migrants $[4,6]$. The accumulation of stressors leading to deterioration in migrants' health over time have been explained by the 'exhausted migrant theory' [7]. Others have suggested that the migration experience in itself could be the cause of this deterioration [8] addressing the very act of migration as a social determinant for migrants' health [9].

Despite forced migrants' exposures to stressful events, there is also increasing evidence of positive mechanisms like post-stress growth, described as positive changes following adversity [10], and resilience, which is characterized by the ability to exhibit a stable health trajectory in difficult times [11]. Consequently, both adverse conditions rendering forced migrants susceptible for health disparities and the sources of resilience and growth must be considered in attempting to understand migrant health [12]. Furthermore, these factors need to be understood in synergy with contextual factors as well as embedded in a life trajectory, highlighting the different migration stages [13].

Although the body of evidence in terms of morbidity and mortality of migrants in host countries is growing, research on forced migrants throughout their often long journeys continues to be scarce [4], and has largely been limited to cross-sectional designs [14]. Also, previous research on forced migration has focused mainly on mental health $[2,15]$, often centered on negative health outcomes, predominantly in torture and trauma victims. Knowledge of overall and general health in non-clinical refugee populations remains insufficient.
Self-rated health (SRH) has proven to be a valuable predictor of all-cause mortality and morbidity [16, 17], including in minority populations [2], and is widely used in health monitoring and to research health inequalities. Quality of life (QoL) is considered a fundamental construct in public health that reflects complete wellbeing, going beyond old paradigms viewing health as merely the absence of disease [18].

Migration is a global, multifaceted, and dynamic phenomenon in which the migration experience in itself constitutes an important segment of the health trajectory $[8,9,13]$. In line with recommendations to address multiple phases of the migratory process [3] we aimed to assess general health among Syrian refugees following their health trajectory from a transit setting to after resettlement using a salutogenic approach. Specifically, our research questions are: 1) how does SRH and QoL of forced migrants change from the transit phase to the early resettlement phase? 2) Which factors (sociodemographic, social support, and migration related) can be identified as modifiers of change? As a second aim, we sought to compare our participants QoL-scores with international samples of QoL used as reference points against which we can interpret our findings. We hypothesized that our cohort of forced migrants would have a stable or decreasing health status after resettlement, as a consequence of post-migration stressors such as acculturation stress, poor access to healthcare, cultural discontinuity, loss of social support and perceived stigma and discrimination $[2,3,19]$.

\section{Methods}

Data for this study were from the CHART project (Changing health and healthcare needs among the Syrian refugee trajectory to Norway [20]), designed with a trajectory perspective to investigate refugee health over time. The reporting follows the STROBE statements for cohort studies.

\section{Study design and participants}

This is a prospective longitudinal study assessing adult Syrian refugees under the UNHCRs international protection mandate admitted for resettlement to Norway at two time points. Baseline measures were gathered through a self-administered survey in Arabic in Lebanon between August 2017 and April 2018 in collaboration with the International Organization for Migration (IOM). Inclusion criteria were Syrian nationals from 16 and above attending mandatory pre-departure educational activities in the given time period, a total of 514 persons. Exclusion criteria were unaccompanied refugee minors between 16 to 18 years and severe mental disorder. However, no one was excluded based on mental health. The questionnaire was distributed during class 
time under the supervision of trained bilingual staff with cultural competence, available to assist persons with low health literacy, illiteracy or low Arabic language proficiency, and to pick up signs of mental distress in case of re-traumatization. Participants were compensated with the approximate equivalent of \$10 USD after completing the baseline questionnaire. After arrival in Norway, the study participants were settled in 134 different municipalities throughout the country. Hence, follow-up measures were gathered through telephone interviews by Arabic-speaking study personnel. The Norwegian Directorate of Integration and Diversity and the municipalities' immigration units provided contact information for the participants after resettlement. A total of 506 eligible subjects were accepted to participate (98\%) in the study at baseline, out of whom 464 (92\%) were confirmed resettled in Norway and 353 of 464 (76\%) followed-up (Additional file 1).

\section{Dependent variables}

In this study, we use two indicators for health as main outcomes: SRH and QoL. We have applied a salutogenic approach that is reflected in the selection and categorization of variables.

\section{Self-rated health}

As a proxy for general health, SRH was assessed using the single-item question: How do you consider your health at the moment? This question is answered using a five-point response scale from very poor to very good. The item was dichotomized into a binary measure distinguishing between Good and Very Good compared with Very poor, Poor and Neither. The SRH measure has shown reliability and validity among Arabic speakers and within refugee populations $[14,21]$.

\section{Quality of life}

QoL was measured using the WHO Quality of Life Scale (WHOQOL-BREF). The WHOQOL-BREF was selected because it was developed as a transcultural instrument and has demonstrated good psychometric properties, reliability, and validity among Arabic speakers [22]. The instrument comprises 24 items measuring four domains; physical health (seven items), psychological health (six items), social relationships (three items) and environment (eight items). The physical health domain entails questions on pain, medical treatment, energy, sleep, mobility and capacity. The psychological domain includes questions on concentration, self-esteem, meaningfulness and positive and negative feelings and thoughts. The social domain focuses on satisfaction with relationships, practical social support and sex-life. The environmental domain pertains to questions on safety and security, access to healthcare, financial recourses and physical environment. Each item is rated on a 5-point Likert scale with a higher score denoting a better QoL on the corresponding domain. Raw scores were transformed creating domain scores within the range of $4-20$ by multiplying the average of the items in each domain by four, in accordance with instructions from the manual. Cronbach's alpha for the total scale for the present sample is 0.8 .

\section{Independent variables \\ Sociodemographic variables}

The questionnaire included sociodemographic variables such as age, gender, mother tongue, marital status, number of children and years of schooling. We also inquired on migration related factors such as time since flight from Syria, time since arrival in Lebanon, number of transit countries before arriving in Lebanon, migrating alone or with family, and residence permit in Lebanon. In addition, we assessed Health Literacy through the single-item literacy screener (SILS): "How often do you need help reading written material from your doctor or pharmacy?" Possible responses are: Never (1), Rarely (2), Sometimes (3), Often (4), and Always (5). Scores higher than 2 point to difficulties with reading health-related material. We created a binary measure and used the variable high health literacy defined as responses $\leq 2$.

\section{Social support}

Perceived social support was measured with The ENRI CHD Social Support instrument (ESSI), a short validated self-report measure that assesses the four defining elements of social support: emotional, instrumental, informational, and appraisal with 7 items [23]. A total score is the sum of all items with higher scores indicating better social support. We created a binary measure for high social support defined as having answered $>2$ on at least two of the seven items and a total score of $>18$ based on the definition of low-social support by the ENRICHD investigators [23]. ESSI has previously been validated among Syrian refugees [24]. Cronbach's alpha for the present sample is 0.85 .

Questions not already validated, such as demographic questions and migration related questions went through a translation process based on the ISPOR principles of good practice guidelines [25]. We included the following steps; two independent forward translations, reconciliation of the forward translation into one translation, back translation, harmonization, cognitive debriefing among a group of 6 respondents and proof reading.

\section{Statistical analysis}

Descriptive data were presented as frequencies and percentages for categorical variables and as median with inter-quartile range (IQR) for continuous variables. Sensitivity analyses between the participants and the loss to 
follow up group were conducted using $\chi^{2}$-statistics and independent group's $t$-tests. We analyzed the longitudinal data using generalized estimating equations (GEE) in long format with "wave" as a binary covariate to evaluate change in outcome from baseline to follow-up. The GEE method accounts for the non-independence of repeated data from the same subject. For binary outcomes we applied a log-link and binomial distribution and reported exponentiated regression coefficients as risk ratios (RR) with 95\% CI. For continuous outcomes we applied an identity link and Gaussian distribution and reported regression coefficients (B) with $95 \%$ CI. To view our results in relation to other populations, we presented mean values of the WHOQOL-BREF domains together with mean values from Skevington et al. [26]. Their research is based on a sample of 11,830 adults from 23 countries across the globe, including Norway. We compare our sample with both the total sample of 11,830 subjects as well as with only the Norwegian sample of 1047 subjects, separately. To evaluate potential effect modifiers for change in outcomes over time we stratified by various characteristics measured at baseline in Lebanon (gender, age, ethnicity, marital status, education, level of health literacy, level of social support (ESSI), time in transit, multiple transit countries, residence permit in Lebanon, migrating alone) and incorporated interaction terms between the covariates and wave in the GEE models to test for significant differences in change over time for different subgroups. Missing values were handled through list wise deletions. An alpha value of 0.05 was considered statistically significant. We analyzed the data using STATA/IC software, version 15.1, (StataCorp LLC, Texas, USA).

\section{Results}

A total of 353 subjects completed both assessments (baseline and follow-up) resulting in an attrition rate of 24\% (Additional file 1). The most common reasons for loss-to-follow-up from Lebanon to Norway was not answering the phone/unreachable after a minimum of three attempts and declining participation. Apart from higher health literacy among respondents $(56 \%$ versus $45 \%)$, no statistically significant differences in characteristics were seen between responders and non-responders (Additional file 2).

\section{Demographics at baseline}

The overall median age of the cohort was 34 years (IQR 27-41), and 49\% were males (Table 1). Participants had an average of 8 years of schooling and three out of four respondents were married (75\%). Most of the participants had been migrants for approximately five years at baseline. A majority had high health literacy (56\%) and approximately one third (35\%) had high social support.
Table 1 Sociodemographic and migration related factors at baseline, $N=353$

\begin{tabular}{|c|c|c|}
\hline SOCIODEMOGRAPHIC FACTORS & & \\
\hline Gender (n, \%) & & \\
\hline Women & 181 & 51 \\
\hline Men & 171 & 49 \\
\hline Age in years (median, IQR) & 34 & $\begin{array}{l}27- \\
41\end{array}$ \\
\hline Mother tongue $(n, \%)$ & & \\
\hline Arabic & 335 & 95 \\
\hline Kurmanji & 15 & 4 \\
\hline Marital status (n, \%) & & \\
\hline Married & 265 & 75 \\
\hline Living with partner among married & 260 & 98 \\
\hline Number of children (median, IQR) & 4 & $3-5$ \\
\hline Education in years (median, IQR) & 8 & $6-10$ \\
\hline High health literacy ${ }^{a}(n, \%)$ & 195 & 56 \\
\hline High social support ${ }^{b}(n, \%)$ & 123 & 35 \\
\hline MIGRATION RELATED FACTORS & & \\
\hline $\begin{array}{l}\text { Time since flight from Syria at baseline in years (median, } \\
\text { IQR) }\end{array}$ & 5 & $4-6$ \\
\hline $\begin{array}{l}\text { Time since arrival in Lebanon at baseline in years } \\
\text { (median, IQR) }\end{array}$ & 5 & $4-5$ \\
\hline Been in other transit country before Lebanon $(n, \%)$ & 20 & 6 \\
\hline No residence permit in Lebanon at baseline $(n, \%)$ & 242 & 69 \\
\hline Migrating alone to Lebanon (n, \%) & 55 & 16 \\
\hline
\end{tabular}

${ }^{a}$ High health literacy defined as scores $\leq 2 .{ }^{b} H i g h$ social support defined as $>2$ on at least two of the seven items and a total score of $>18$

\section{Changes in health from baseline to follow-up and comparison to other populations}

Table 2 presents the main outcomes at baseline and follow-up. More than half of the respondents rated their health as good at baseline with a non-significant increase at follow-up RR, 95\%CI: $1.1(1.0,1.2), P=0.072$. In the QoL domains, the highest domain scores were observed in physical health and in social relationships. Both domains showed a statistically significant increase at follow-up from 13.7 to $15.7 \mathrm{~B}, 95 \% \mathrm{CI}: 1.9(1.6,2.3)$ and from 13.7 to $15.3 \mathrm{~B}, 95 \% \mathrm{CI}$ : $1.6(1.2,2.0)$, respectively. The lowest scores at baseline were observed in questions relating to the environment followed by the psychological domain but these also increased at follow-up, from 9.0 to $14.0 \mathrm{~B}, 95 \% \mathrm{CI}: 5.1(4.7,5.4)$ and from 12.8 to 14.5 B, 95\%CI: $1.7(1.3,2.0)$, respectively. Overall, all the QoL scores were significantly higher in the follow-up assessment.

In Fig. 1, we compare changes in mean values with data from the international field trials of the WHOQOL-group, using both the sum of all field countries' mean QoL-scores as well as Norwegian QoLscores as reference points, separately [26]. At baseline, 
Table 2 Changes in prevalence (\%) in dichotomous outcome (SRH) and mean (SD) score for continuous outcome (WHOQOL-BREF four domain scores, range 4-20) from baseline to follow-up, $N=353$

\begin{tabular}{|c|c|c|c|c|c|c|}
\hline \multirow[b]{2}{*}{ Self-rated health } & \multicolumn{2}{|c|}{ Baseline } & \multicolumn{2}{|c|}{ Follow-up } & \multirow{2}{*}{$\begin{array}{l}\text { Change } \\
\text { RR }(95 \% \mathrm{Cl})\end{array}$} & \multirow[t]{2}{*}{$P$-value } \\
\hline & $\mathrm{N}$ & n (\%) & $\mathbf{N}$ & n (\%) & & \\
\hline \multirow[t]{2}{*}{ Good SRH } & 349 & $203(58)$ & 351 & $222(63)$ & $1.1(1.0,1.2)$ & 0.072 \\
\hline & \multicolumn{2}{|c|}{ Baseline } & \multicolumn{2}{|c|}{ Follow-up } & Change & \\
\hline Quality of life (WHOQOL-BREF) & $\mathrm{N}$ & Score (SD) & $\mathrm{N}$ & Score (SD) & B $(95 \% \mathrm{Cl})$ & \\
\hline Physical health (Domain 1) & 353 & $13.7(2.7)$ & 353 & $15.7(2.8)$ & $1.9(1.6,2.3)$ & $<0.001$ \\
\hline Psychological health (Domain 2) & 353 & $12.8(2.7)$ & 353 & $14.5(2.3)$ & $1.7(1.3,2.0)$ & $<0.001$ \\
\hline Social relationships (Domain 3) & 353 & $13.7(3.0)$ & 352 & $15.3(2.8)$ & $1.6(1.2,2.0)$ & $<0.001$ \\
\hline Environment (Domain 4) & 353 & $9.0(2.4)$ & 353 & $14.0(2.2)$ & $5.1(4.7,5.4)$ & $<0.001$ \\
\hline
\end{tabular}

Abbreviations: $R R$ Relative risk. $C l$ Confidence interval. SD Standard deviation

mean values for the physical, psychological and environmental domains were significantly lower than both international and Norwegian reference scores but improved to nearly the same levels at follow-up. The social relationship domain matched the international and Norwegian reference scores at baseline and surpassed these levels at follow-up.

\section{Effect modifications}

Risk ratios and regression coefficients from stratified models with test for effect modification are reported in Table 3. We found a statistically significant improvement in the proportion of good SRH among men, but not among women, with a statistically significant interaction effect by gender. The improvement in social relationships (domain 3) and environment (domain 4) was also significantly larger in men. We also observed an interaction by age in the psychological domain (domain
2) with statistically significant improvement only among participants $<40$ years of age. For marital status, the only statistically significant interaction was observed in the environmental domain (domain 4), with larger improvement among those who were married. When stratifying on level of social support (ESSI), there was a significantly stronger improvement among those with low social support at baseline in SRH and in the psychological and environment domain (domain 2 and 4). In terms of having a residence permit in Lebanon or not, statistically significant improvement in good SRH and social relationships (domain 3) was seen only among participants with no residence permit at baseline.

In Additional file 3, prevalence of good SRH and mean scores for the QoL domains at baseline and follow-up with stratification on variables showing statistically significant effect modification are reported. Here we can see that participants with low social support at baseline

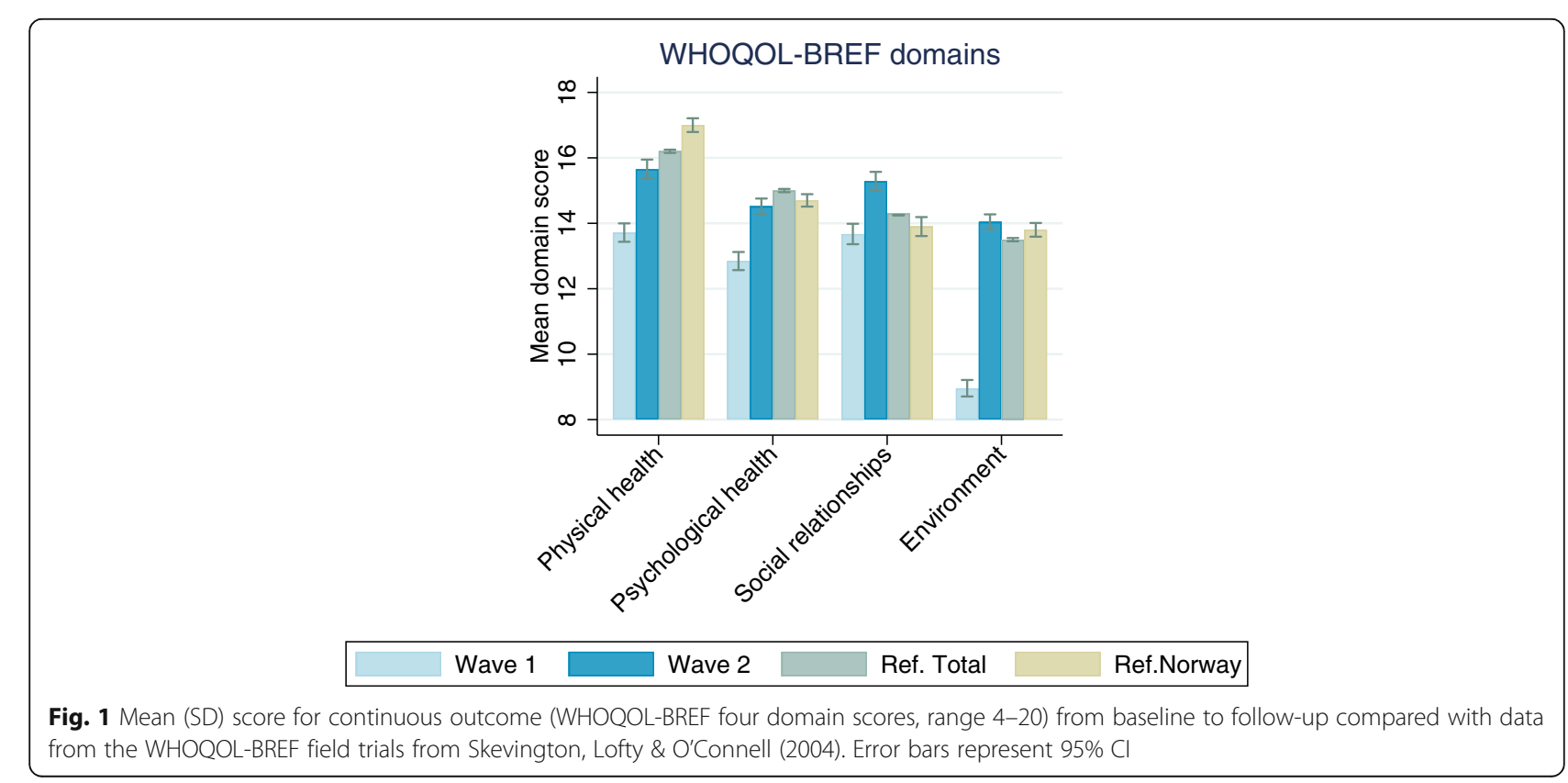


Table 3 Effect modification of change in dichotomous outcome (SRH) and continuous outcomes (four domains of WHOQOL-BREF) by selected sociodemographic and migration-related variables using interaction terms in generalized estimating equations, $N=353$

\begin{tabular}{|c|c|c|c|c|c|c|c|c|c|c|}
\hline & \multicolumn{2}{|l|}{ Good SRH } & \multicolumn{2}{|c|}{ Physical health } & \multicolumn{2}{|c|}{ Psychological health } & \multicolumn{2}{|c|}{ Social relationships } & \multicolumn{2}{|l|}{ Environment } \\
\hline & RR (95\% Cl) & $P$ & $\mathrm{~B}(95 \% \mathrm{Cl})$ & $P$ & $\mathrm{~B}(95 \% \mathrm{Cl})$ & $P$ & $\mathrm{~B}(95 \% \mathrm{Cl})$ & $\mathbf{P}$ & B (95\% Cl) & $P$ \\
\hline \multicolumn{11}{|l|}{ Gender } \\
\hline Male & $1.2(1.1,1.4)$ & & $2.2(1.7,2.7)$ & & $1.9(1.3,2.4)$ & & $2.1(1.5,2.6)$ & & $5.5(5.0-5.9)$ & \\
\hline Female & $1.0(0.6,1.1)$ & & $1.7(1.2,2.1)$ & & $1.5(1.1,1.9)$ & & $1.2(0.6,1.7)$ & & $4.7(4.2,5.1)$ & \\
\hline Interaction test & & $0.04^{*}$ & & 0.157 & & 0.293 & & $0.027^{*}$ & & $0.023^{*}$ \\
\hline \multicolumn{11}{|l|}{ Age } \\
\hline$<40$ years & $1.1(1.0,1.2)$ & & $2.1(1.8,2.5)$ & & $1.9(1.5,2.3)$ & & $1.6(1.2,2.1)$ & & $5.1(4.7,5.5)$ & \\
\hline$\geq 40$ years & $1.1(0.9,1.4)$ & & $1.3(0.5,2.1)$ & & $0.9(0.1,1.6)$ & & $1.4(0.7,2.1)$ & & $5.0(4.3,5.7)$ & \\
\hline Interaction test & & 0.793 & & 0.056 & & $0.016^{*}$ & & 0.533 & & 0.677 \\
\hline \multicolumn{11}{|l|}{ Marital status } \\
\hline Married & $1.1(1.0,1.3)$ & & $2.0(1.6,2.5)$ & & $1.8(1.4,2.2)$ & & $1.5(1.0-1.9)$ & & $5.2(4.9,5.7)$ & \\
\hline Other & $1.0(0.9,1.1)$ & & $1.6(1.0,2.2)$ & & $1.2(0.6,1.9)$ & & $2.1(1.3,2.8)$ & & $4.5(3.8,5.2)$ & \\
\hline Interaction test & & 0.478 & & 0.243 & & 0.121 & & 0.202 & & $0.048^{*}$ \\
\hline \multicolumn{11}{|c|}{ High social support (ESSI) } \\
\hline Yes & $0.9(0.8,1.1)$ & & $1.5(0.8,2.1)$ & & $0.8(0.2,1.4)$ & & $1.4(0.8,1.9)$ & & $4.4(3.9,5.0)$ & \\
\hline No & $1.2(1.1,1.3)$ & & $2.2(1.8,2.6)$ & & $2.1(1.7,2.5)$ & & $1.7(1.2,2.3)$ & & $5.4(5.0,5.8)$ & \\
\hline Interaction test & & $0.01^{*}$ & & 0.062 & & $0.001^{*}$ & & 0.337 & & $0.006^{*}$ \\
\hline \multicolumn{11}{|c|}{ Residence permit in Lebanon } \\
\hline Yes & $0.9(0.8,1.1)$ & & $1.8(1.2,2.4)$ & & $1.5(0.8,2.2)$ & & $1.0(0.2,1.7)$ & & $5.0(4.4,5.5)$ & \\
\hline No & $1.2(1.1,1.3)$ & & $2.0(1.6,2.4)$ & & $1.7(1.3,2.1)$ & & $1.9(1.5,2.4)$ & & $5.1(4.7,5.6)$ & \\
\hline Interaction test & & $0.026^{*}$ & & 0.519 & & 0.614 & & $0.035^{*}$ & & 0.642 \\
\hline
\end{tabular}

Statistically significant results are marked with an asterisk $(p<0.05)$. Abbreviations: $\mathrm{SRH}=$ Self-rated health. $\mathrm{P}=\mathrm{p}$-value. $\mathrm{RR}=$ Relative risk. $\mathrm{Cl}=\mathrm{Confidence}$ interval. $B=$ beta coefficient

also had low levels of good SRH, psychological health, social relationships and environmental factors with a subsequent increase in each of these variables at follow-up.

Changes in the main outcomes did not differ by level of education, health literacy, time in transit or if migrating alone or with family (not shown in table).

\section{Discussion}

Our study used longitudinal data to examine changes in SRH and QoL among Syrian refugees at two stages of their migration path. Overall, we found that SRH remained stable while QoL increased significantly in the short follow-up period of one year. Furthermore, our results suggest that gender, age and factors connected to the situation in transit (social support and residence permit in transit country) are important effect modifiers of change in SRH and QoL. The generally positive outcomes from this study lend credence to the notion of refugees' inherent health resources stimulating growth and resilience [27]. A positive subjective health outcome is an essential means to successful integration, at the same time as successful integration enables good health [28].
Over half of the refugees rated their health as good at baseline (58\%). This finding corresponds to levels of SRH measured in Syrian adults residing in pre-war Syria (55.3\%) [29] and is also similar to previous findings on SRH among forced migrants resettled in high income countries, ranging from 58 to $64 \%$ [30, 31]. In contrast, in the general Norwegian population, over $70 \%$ rated their health as good [32]. Thus, we postulate that our cohort of forced migrants do not have an evident health advantage when compared with their final host population, which contradicts the healthy migrant effect/paradox $[4,6]$. Notably, the SRH level increased marginally but non-significantly after only one year in resettlement.

Additionally, we found that the pre-arrival QoL scores for physical health, psychological health, and environment were rated significantly lower than the mean scores from the WHOQOL-BREF international field trials [26]. The physical and psychological domain improve significantly after resettlement but remain lower than international reference scores. In the environmental domain, mean QoL-scores surpass the levels of international reference scores after resettlement. Only a few previous studies have explored the concept of QoL specifically in forced migrants. Some of them found low 
scores in the environmental domain [33, 34] while others did not [35], but comparison is impeded by heterogeneity in the samples, apparent differences in migrant legal status and differences in countries' reception schemes upon arrival. In our study, the lowest ratings at baseline were seen in the environment domain, which contains facets on financial resources, safety and security, accessibility of healthcare services and physical environment. Low scores could be attributed to circumstances observed in refugee settlements where unstable living conditions and poor provision of health services are prevalent. Our finding that all three domain scores: physical, psychological, and environment, improved after one year's stay in the host country supports this theory. In addition, supportive resources upon arrival and favorable integration policies might have contributed to outweigh the effect of post-migration stressors [13].

The social relationship domain scores were lower than international reference scores at baseline but exceeded both international and Norwegian reference scores at follow-up [26]. Even though migration is a main cause of family disruption, most participants in our sample were resettled together with other family members, which might partially explain the high scores in social relationships. Some studies have reported favorable social relationships scores among forced migrants [35, 36] while others found results pointing in the opposite direction [37]. A high social capital has been identified as an important protective factor for poor mental health outcomes [38] and in sustaining refugee resilience and acculturation in the resettlement process [39].

We found stronger improvement in SRH and two out of four QoL domains among men compared to women. These gender-related differences are comparable with evidence from previous research reporting worse health outcomes for female refugees [2, 30]. A gender-gap in $\mathrm{SRH}$-measures has for long been conceptualized by researchers and has been attributed to a combination of biological and socio-behavioral differences [40]. In addition to known gender differences in $\mathrm{SRH}$, the migration experience most likely affects men and women differently [3]. In the psychological domain, there was a larger improvement among younger participants, aged less than 40. This supports the notion of greater resilience seen in younger refugees [2, 41]. Moreover, we found that participants with low social support while in Lebanon had stronger improvement in SRH and QoL. Since there is a strong correlation between social support, SRH and QoL at baseline and their baseline measures were much lower than participants with high social support, this improvement indicates a larger "catch-up" for a group with an inferior starting point. It also means that within the right circumstances, an increase in SRH and QoL can be achieved regardless of your starting level of social support. The same catch-up phenomenon was seen for the ones who did not have a residence permit in Lebanon. Again, both these findings could point to internal resources in the refugee population enabling adjustment and growth after adversity. Contrary to our expectations, education - a social determinant of health, was not identified as a positive modifier of improvement. This could be attributed to the negative effect of losing your status prevailing over the protective effect of education [2]. Only a few migrated without family $(16 \%)$ and it is possible that this small number made us unable to detect significant interactions for this variable.

\section{Strengths and limitations}

The main strength of our study is the unique pre-arrival assessment that enabled us to trace refugee health outcomes before and after arrival to the host country using a longitudinal design. To our knowledge, this is a novel contribution to the research field allowing us to shed light on the sequential changes in health in a people moving from completely disparate settings. Secondly, we have a high response rate. In joint, the use of only validated instruments and a high response rate supports the internal validity of the study.

However, our findings should be interpreted in the context of the following limitations. Primarily, since there are no available registers on forced migrants during migration, we cannot state to which degree our sample is representative for the target population. This lack of an overall sample frame is a common limitation to observational studies on migrant health [42]. To compensate for this, efforts were put in the design to increase representativeness by inviting all the persons from Syria that were to be resettled to Norway in a given time period, as well as having a long recruitment period and recording of non-participation. Another limitation could be the deliberate change in assessment method from mainly self-completed questionnaire at baseline to telephone interviews at follow-up that introduces the possibility of interviewer bias. We used a short follow-up time that gives us important insight into the first phase of resettlement. However, we lack a long-term perspective. Prior research has shown deterioration in health over time [43] which warrants further longitudinal follow-up.

Our findings of an overall healthy cohort of refugees showing improvement in QoL in a short period of time provide important and novel information about a phase of the migration trajectory where little previous knowledge exists. From a clinical point of view, this information can encourage a shift in attention from pathogenesis to salutogenesis [44]. Recognizing positive health outcomes and refugees' inherent health resources 
is important in the developing of interventions to bolster growth, resilience, and adaptation for the general refugee. In a policy-making setting, our findings suggest that women and older refugees should be subjected to a special effort to improve health. Our findings are also important in informing political and public discourse, nuancing the perception of refugees as a group with an inferior health status. We recommend more in-depth research to understand the mechanisms behind this rapid increase in QoL so that it can be sustained.

\section{Conclusion}

We found stability in SRH and improvement in QoL in the early resettlement phase of refugees, more in younger age and among men compared to women. In addition, the social relationship and environment domain of QoL surpassed the levels of international reference scores after resettlement. Policy-makers and health care professionals should acknowledge that health of refugees is dynamic and can show rapid improvement after resettlement. To promote health equity and facilitate migration reception and integration, both short-term and long-term health outcomes should be taken into account.

\section{Supplementary information}

Supplementary information accompanies this paper at https://doi.org/10. 1186/s12939-020-01300-6.

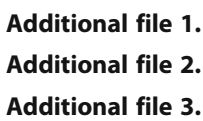

\section{Acknowledgments}

We greatly acknowledge the International Organization for Migration (IOM) and The Norwegian Directorate of Integration and Diversity for aid in the data collection process. We would also like to thank the Research Council of Norway for funding this study. The funder had no role in study design, data collection, data analysis, data interpretation, or writing of the report.

\section{Authors' contributions}

All authors contributed to the study conception and design. Material preparation, data collection and analysis were performed by JHY, EMS, JI and ED. The first draft of the manuscript was written by JHY and all authors commented on previous versions of the manuscript. All authors read and approved the final manuscript.

\section{Funding}

This study was funded by The Research Council of Norway (grant 269835).

\section{Availability of data and materials}

The datasets generated for the present study are not publicly available due to data protection regulations in Norway.

\section{Ethics approval and consent to participate}

Ethical approval was obtained from the Regional Committee for Medical and Health Research Ethics of South East Norway (ref. no. 2017/377) and by the International Organization for Migration and was conducted in accordance with the Declaration of Helsinki. Participants provided written consent at baseline and verbal consent at follow-up prior to participation. Participants were recruited to the study after they had been granted refugee status and a residence permit in Norway to avoid any unjustified expectations. Confidentiality was ensured to all participants including those with illegal status in Lebanon. Data were de-identified and stored on a protected server. Permissions to use the validated survey instruments were obtained from all copyright holders.

\section{Consent for publication}

Not applicable.

\section{Competing interests}

The authors declare that they have no competing interests.

\section{Author details}

${ }^{1}$ Department of Global Public Health and Primary Care, University of Bergen, PO Box 7800, 5020 Bergen, Norway. ${ }^{2}$ Unit for Migration and health. Norwegian Institute of Public Health, PO Box 222 Skøyen, 0213 Oslo, Norway. ${ }^{3}$ Department of Psychosocial Health, University of Agder, PO Box 422, 4604 Kristiansand, Norway.

Received: 7 July 2020 Accepted: 13 October 2020

Published online: 27 October 2020

\section{References}

1. Resolution 70/1. Transforming our world: the 2030 agenda for sustainable development. Resolution adopted by the general assembly on 25 September 2015. New York: United Nations; 2015. http://www.un.org/ga/ search/view_doc.asp?symbol=A/RES/70/1\&Lang=E. Accessed 06 June 2020.

2. Porter M, Haslam N. Predisplacement and postdisplacement factors associated with mental health of refugees and internally displaced persons: a meta-analysis. JAMA. 2005;294(5):602-12.

3. Zimmerman C, Kiss L, Hossain M. Migration and health: a framework for 21st century policy-making. PLoS Med. 2011;8(5):e1001034.

4. Abubakar I, Aldridge RW, Devakumar D, et al. The UCL-Lancet Commission on migration and health: the health of a world on the move. Lancet. 2018; 392:2606-54.

5. Grabovschi C, Loignon C, Fortin M. Mapping the concept of vulnerability related to health care disparities: a scoping review. BMC Health Serv Res. 2013;13:94 (2013).

6. Helgesson $M$, Johansson $B$, Nordquist $T$, et al. Healthy migrant effect in the Swedish context: a register-based, longitudinal cohort study. BMJ Open. 2019;9:e026972

7. Bollini $\mathrm{P}$, Siem $\mathrm{H}$. No real progress towards equity: health of migrants and ethnic minorities on the eve of the year 2000. Soc Sci Med. 1995; 41(6):819-28

8. Jasso G, Massey DS, Rosenzweig MR, Smith JP. Immigrant health: selectivity and acculturation. In: Anderson NB, Bulatao RA, Cohen B, editors. Critical perspectives on racial and ethnic differences in health in late life. Washington DC: National Academy Press; 2004. p. 227-66.

9. Castañeda H, Holmes SM, Madrigal DS, Young ME, Beyeler N, Quesada J. Immigration as a social determinant of health. Annu Rev Public Health. 2015:36:375-92.

10. Tedeschi RG, Calhoun LG. Posttraumatic growth: conceptual foundations and empirical evidence. Psychol Inq. 2004;15:1-18.

11. Bonanno GA. Loss, trauma, and human resilience: have we underestimated the human capacity to thrive after extremely aversive events. Am Psychol. 2004;59:20.

12. IOM. Health of migrants: resetting the agenda. Report of the second global consultation. Colombo, Sri Lanka, 2017. https://publications.iom.int/system/ files/pdf/gc2_srilanka_report_2017.pdf. Accessed 06 June 2020.

13. Edberg M, Cleary S, Vyas A. A trajectory model for understanding and assessing health disparities in immigrant/refugee communities. J Immigr Minor Health. 2011;13(3):576-84.

14. Dowling A, Enticott J, Russell G. Measuring self-rated health status among resettled adult refugee populations to inform practice and policy - a scoping review. BMC Health Serv Res. 2017;17(1):1-9.

15. Steel Z, Chey T, Silove D, Marnane C, Bryant RA, van Ommeren M. (2009). Association of torture and other potentially traumatic events with mental health outcomes among populations exposed to mass conflict and displacement: a systematic review and meta-analysis. JAMA. 2009;302(5): 537-49. 
16. Idler EL, Benyamini Y. Self-rated health and mortality: a review of twentyseven community studies. J Health Soc Behav. 1997;38(1):21-37.

17. DeSalvo K, Bloser M, Renolds K, Jiang H, Munter P. Mortality prediction with a single general self-rated health question. A meta-analysis. J Gen Intern Med. 2006;21(3):267-75.

18. Testa MA, Simonson DC. Assessment of quality-of-life outcomes. N Engl J Med. 1996;334(13):835-40.

19. Chen W, Hall BJ, Ling L, Renzaho AM. Pre-migration and post-migration factors associated with mental health in humanitarian migrants in Australia and the moderation effect of post-migration stressors: findings from the first wave data of the BNLA cohort study. Lancet Psychiatry. 2017;4(3):218-29.

20. Website: Changing health and healthcare needs among the Syrian refugee trajectory to Norway. https://www.uib.no/en/generalpractice/chart). Assessed June 2020.

21. Abdulrahim S, El Asmar K. Is self-rated health a valid measure to use in social inequities and health research? Evidence from the PAPFAM women's data in six Arab countries. Int J Equity Health. 2012;11:53.

22. Ohaeri JU, Awadalla AW. The reliability and validity of the short version of the WHO quality of life instrument in an Arab general population. Ann Saudi Med. 2009;29(2):98-104.

23. ENRICHD Investigators. Enhancing recovery in coronary heart disease: baseline characteristics. Am J Cardiol. 2001;88:316-22.

24. Gottvall M, Vaez M, Saboonchi F. Social support attenuates the link between torture exposure and post-traumatic stress disorder among male and female Syrian refugees in Sweden. BMC Int Health Hum Rights. 2019;19(1):28.

25. Wild D, Grove A, Martin M, et al. Principles of good practice for the translation and cultural adaptation process for patient-reported outcomes (PRO) measures: report of the ISPOR task force for translation and cultural adaptation. Value Health. 2005:8:94-104.

26. Skevington SM, Lofty M, O'Connell KA. The World Health Organization's. WHOQOL-BREF quality of life assessment: psychometric properties and results of the international field trials. A report of the WHOQOL group. Qual Life Res. 2004;4(2):299-310.

27. Teodorescu DS, Siqveland J, Heir T, Hauff E, Wentzel-Larsen T, Lien L. Posttraumatic growth, depressive symptoms, posttraumatic stress symptoms, post-migration stressors and quality of life in multi-traumatized psychiatric outpatients with a refugee background in Norway. Health Qual Life Outcomes. 2012;10:84.

28. United Nations High Commissioner for Refugees. Refugee resettlement: an international handbook to guide reception and integration. Geneva: United Nations High Commissioner for Refugees; 2002. http://www.unhcr.org/4a2 cfe336.html. Accessed 28 May 2020.

29. Asfar T, Ahmad B, Rastam S, Mulloli TP, Ward KD, Maziak W. Self-rated health and its determinants among adults in Syria: a model from the Middle East. BMC Public Health. 2007;7:177.

30. Dowling A, Enticott J, Kunin M, Russell G. The association of migration experiences on the self-rated health status among adult humanitarian refugees to Australia: an analysis of a longitudinal cohort study. Int J Equity Health. 2019;18(1):130.

31. Jamil H, Nassar-McMillan S, Lambert R, Wangd Y, Ager J, Arnetz B. Pre- and post-displacement stressors and time of migration as related to self-rated health among Iraqi immigrants and refugees in Southeast Michigan. Med Confl Surviv. 2010;26(3):207-22.

32. Von dem Knesebeck O, Geyer S. Emotional support, education and selfrated health in 22 European countries. BMC Public Health. 2007;7:272 (2007).

33. Leiler A, Bjärtå A, Ekdahl J, et al. Mental health and quality of life among asylum seekers and refugees living in refugee housing facilities in Sweden. Soc Psychiatry Psychiatr Epidemiol. 2019;54:543-51.

34. Laban CJ, Komproe IH, Gernaat HBPE, et al. The impact of a long asylum procedure on quality of life, disability and physical health in Iraqi asylum seekers in the Netherlands. Soc Psychiat Epidemiol. 2008;43:507 (2008).

35. Aziz I, Hutchinson CV, Maltby J. Quality of life of Syrian refugees living in camps in the Kurdistan region of Iraq. PeerJ. 2014;2:e670.

36. Löfvander M, Rosenblad A, Wiklund T, Bennström H, Leppert J. A casecontrol study of self-reported health, quality-of-life and general functioning among recent immigrants and age- and sex-matched Swedish-born controls. Scand J Public Health. 2014;42(8):734-42.

37. Abdo N, Sweidan F, Batieha A. Quality-of-life among Syrian refugees residing outside camps in Jordan relative to Jordanians and other countries. PeerJ. 2019;7:e6454.
38. Ghazinour M, Richter J, Eisemann M. Quality of life among Iranian refugees resettled in Sweden. J Immigr Health. 2004;6:71-81.

39. Lamba NK, Krahn H. Social capital and refugee resettlement: the social networks of refugees in Canada. Int Migrat Integrat. 2003;4:335-60.

40. Oksuzyan A, Juel K, Vaupel JW, Christensen K. Men: good health and high mortality. Sex differences in health and aging. Aging Clin Exp Res. 2008; 20(2):91-102.

41. Fazel M, Reed RV, Panter-Brick C, Stein A. Mental health of displaced and refugee children resettled in high-income countries: risk and protective factors. Lancet. 2012;379(9812):266-82.

42. Enticott JC, Shawyer F, Vasi S, et al. A systematic review of studies with a representative sample of refugees and asylum seekers living in the community for participation in mental health research. BMC Med Res Methodol. 2017;17(1):37.

43. Diaz E, Kumar BN, Gimeno-Feliu LA, Calderón-Larrañaga A, Poblador-Pou B, Prados-Torres A. (2015). Multimorbidity among registered immigrants in Norway: the role of reason for migration and length of stay. Tropical Med Int Health. 2015;20(12):1805-14.

44. Lindström B, Eriksson M. Professor Aaron Antonovsky (1923-1994): the father of the salutogenesis. J Epidemiol Commun Health. 2005;59:511.

\section{Publisher's Note}

Springer Nature remains neutral with regard to jurisdictional claims in published maps and institutional affiliations.
Ready to submit your research? Choose BMC and benefit from:

- fast, convenient online submission

- thorough peer review by experienced researchers in your field

- rapid publication on acceptance

- support for research data, including large and complex data types

- gold Open Access which fosters wider collaboration and increased citations

- maximum visibility for your research: over $100 \mathrm{M}$ website views per year

At BMC, research is always in progress.

Learn more biomedcentral.com/submissions 